\title{
Income Inequality is not Harmful for Growth: Theory and Evidence
}

\author{
Hongyi Li and Heng-fu Zou*
}

\begin{abstract}
The paper shows that income inequality may theoretically lead to higher economic growth if public consumption enters the utility function. Empirically, baseline estimations and a sensitivity analysis show that income inequality is positively, and most of the time significantly, associated with economic growth. These findings stand in sharp contrast to the negative association between inequality and growth propounded by Alesins and Rodrik and by Persson and Tabellini.
\end{abstract}

\section{Introduction}

This paper reexamines the relationship between income distribution and economic growth. We consider a more general theoretical framework than Alesina and Rodrik (1994) by dividing government spending into production services and consumption services - the former enter the production function while the latter enter the utility function. With this extension it is found that, within a typical political-economy mechanism (the majority rule) on income taxation, more equal income distribution can lead to higher income taxation and lower economic growth; and in general, income inequality has an ambiguous effect on economic growth. This stands in sharp contrast to the theoreticai result obtained by Alesina and Rodrik, ${ }^{1}$ who focused on the productive services of government spending and found a definite negative link between them.

On the empirical side, we present an extensive statistical analysis to test the relationship between income inequality and economic growth on the basis of a much improved and expanded dataset on income distribution compiled recently by Deininger and Squire (1996). When regressing the GDP growth rate on the Gini coefficients and other typical explanatory variables, the estimated regression coefficients for the Gini coefficients are positive in all cases and even significant in many cases considered here. This empirical finding supports the more general theoretical result of our model.

In section 2 we present a simple model that may give rise to a positive relationship between income inequality and economic growth. Section 3 presents the empirical analysis in which we explain the data and methodology, summarize the results of the base regression, and conduct some sensitivity analysis. Section 4 concludes.

\section{A Simple Model on the Positive Relationship between Income Inequality and Economic Growth}

In this section, we focus on a model that can generace a positive relationship between inequality and growth. Whereas Alesina and Rodrik (1994) follow Barro (1990) to

\footnotetext{
- Li: Faculty of Business Administration, Chinese University of Hong Kong. Hong Kong. Tel: (852) 2609 7796: Fax: (852) 2643-5561; E-mail: hongyi@baf.msmail.cuhk.edu,hk. Zou: Institute for Advanced Studies. Wutuan University, Wuhan, China 430072; and Development Research Group, World Bank, Room MC2.611. 1818 H St. NW, Washington, DC 20433, USA. Tel. (202)473-7939; Fax: (202) 522-1154; E-mail: zou@worldbank.org.
} 
define all government spending as an input in production, we divide government spending into production services and consumption services. This division has already been made by other authors since the seminal contribution by Arrow and Kurz (1970), and explicitly by Barro (see Barro, 1990, section V). In the special case presented here, government spending enters only the utility function.

An individual $i$ has the following CES utility function:

$$
U^{i}=\int_{0}\left[\frac{\left(c_{i}\right)^{1-\theta}-1}{1-\theta}+\ln g\right] e^{-\infty} d t,
$$

where $c_{i}$ is the $i$ th individual's consumption at time $t, i=1, \ldots, N ; N$ is the total number of individuals in this economy; $g$ is total government spending on public services; $0<\theta<\infty$, and $\rho>0$. Empirically, $\theta$ usually takes values from the interval $[1,10]$ as reported by Hall (1988) and also used by King and Rebelo (1990). When $\theta=1$, we have the logarithmic utility function $\ln c^{3}$.

Instead of using the familiar Barro-type production function for this economy, $y=$ $A k^{\alpha} g^{1-\alpha}$, we assume $\alpha=1$ and let the production function take the most popular form in the endogenous-growth literature:

$$
y=A k \text {. }
$$

Here $y$ is the total output, $A>0$, and $k=\sum_{i=1}^{N} k_{i}$, where $k_{i}$ is the capital stock held by individual $i$. As in Barro (1990), $k$ can be interpreted as a combination of both phyzical and human capital. We will argue later that the Barro-type production function combined with the utility function in (1) generates ambiguous results regarding income distribution and economic growth. Thus by using the special case here we can see clearly how income inequality can lead to faster economic growth when government spending is wholly driven by public consumption. The Alesina-Rodrik result is another special case where government spending generates only production services. Of course, the reality is somewhere between these two extremes, expressed as the ambiguity between income distribution and economic growth.

Given a positive tax rate $\tau$ on capital income, individual $i$ 's after-tax income is $(1-\tau) A k_{\text {is }}$ Government spending with an imposed balanced budget at each period $t$ is

$$
g=\tau A \sum_{i=1}^{N} k_{i}=\tau A k .
$$

Individual $i$ accumulates capital as follows:

$$
\frac{d k_{i}}{d t}=(1-\tau) A k_{i}-c_{i}
$$

with initial capital stock given by $\boldsymbol{k}_{i}(0)$.

The income share for individual $i$ is:

$$
\sigma_{i}=\frac{A k_{i}}{A \sum_{-4}^{N} k_{i}}=\frac{k_{i}}{k} .
$$

which is the same as individual $i$ 's wealth (capital) share in the total. An individual with a high $\sigma$ is capital-rich or income-rich, while one with a low $\sigma$ is capital-poor or income-poor. Note that our definition of $\sigma$ is the inverse of the one in Alesina and 
Rodrik (1994) when labor input is assumed to be the same for everyone in the economy.

Individual $i$ maximizes (1) subject to the dynamic constraint in (4). The optimal rates of income growth, consurnption growth and capital accumulation are the same on the balanced path:

$$
\gamma_{i} \equiv \gamma \equiv \frac{d c_{i} / d t}{c_{i}}=\frac{d k_{i} / d t}{k_{i}}=\frac{d y_{i} / d t}{y_{i}}=\frac{(1-\tau) A-\rho}{\theta} .
$$

Because all individuals are alike except for their initial capital holdings, the growth rate will be the same for the $N$ individuals. Therefore, for individual $i$ :

$$
\begin{aligned}
& k_{i}(t)=k_{i}(0) e^{\frac{(1-\tau) A-\rho}{\theta}}, \\
& c_{i}(t)=\frac{\rho-(1-\tau)(1-\theta) A}{\theta} k_{i}(0) e^{\frac{(1-\tau) A-\rho}{\theta},} \\
& \sigma_{i}(t)=\frac{k_{i}(0)}{k(0)} .
\end{aligned}
$$

Because everything is growing at the same rate for all individuals, their income shares remain the same over time and equal their initial capital shares.

To determine the rate of capital income tax, we follow Alesina and Rodrik. First, we solve for the optimal choice of tax rate $\tau_{i}$ if the government intends to maximize individual i's well-being. With relevant substitutions, the objective function of individual $i$ is:

$$
\begin{aligned}
U^{i}= & \frac{\left[\sigma_{i} k(0)\right]^{-\theta}}{(1-\theta)}\left[\frac{\rho-\left(1-\tau_{i}\right)(1-\theta) A}{\theta}\right]^{-\theta}+\frac{\ln \tau_{i}}{\rho} \\
& +\frac{A\left(1-\tau_{i}\right)-\rho}{\theta \rho^{2}}+\text { constant. }
\end{aligned}
$$

Here, the term in the large square brackets is greater than zero for the discounted utility to be bounded.

Its maximization with respect to $\tau_{1}$ yields the following condition:

$$
-A\left[\sigma_{i} k(0)\right]^{1-\theta}\left[\frac{\rho-\left(1-\tau_{i}\right)(1-\theta) A}{\theta}\right]^{-\theta-1}+\frac{1}{\tau_{i} \rho}-\frac{A}{\theta \rho^{2}}=0 .
$$

Then:

$$
\begin{aligned}
& \left\{-\frac{1-\theta^{2}}{\theta} A^{2}\left[\sigma_{i} k(0)\right]^{1-\theta}\left[\frac{\rho-\left(1-\tau_{i}\right)(1-\theta) A}{\theta}\right]^{-\theta-2}-\frac{1}{\tau_{i}^{2} \rho}\right\} d \tau_{i} \\
& =A\left[\sigma_{i} k(0)\right]^{-\theta}\left[\frac{\rho-\left(1-\tau_{i}\right)(1-\theta) A}{\theta}\right]^{-\theta-1} \frac{1-\theta}{\theta} k(0) d \sigma_{i} .
\end{aligned}
$$


In (12), the right-hand side is positive (negative) if $\theta<(>) 1$. The first term on the lefthand side is positive (negative) if $\theta<(>) 1$, while the second term on the left-hand side is always negative. Thus:

$$
\begin{array}{ll}
d \tau_{i} / d \sigma_{i}>0, & \text { if } \theta>1 \\
d \tau_{i} / d \sigma_{i}=0, & \text { if } \theta=1
\end{array}
$$

Since $\theta \in[1,10]$ for empirically relevant analysis as in Hall (1988), we can conclude that empirically $\tau_{i}$ is monotonically increasing in the income share $\sigma_{i}$ Therefore, altering the specific role of government spending overturns the negative relationship between income inequality and the income tax rate in Alesina and Rodrik. But for 0 $<\theta<1$, the first term on the left-hand side is positive while the second term is negative. Therefore the sign for $d \tau d d \sigma_{i}$ is ambiguous.

With the choice of income taxation by majority voting, the median-voter theorem applies here because the preferences are single-peaked. Therefore, the tax rate chosen by the majority rule is just the median voter's preferred choice $\tau_{m}$ with $\tau_{m}$ defined implicitly in

$$
-A\left[\sigma_{m} k(0)\right]^{1-\theta}\left[\frac{\rho-\left(1-\tau_{m}\right)(1-\theta) A}{\theta}\right]^{-\theta-1}+\frac{1}{\tau_{m} \rho}-\frac{A}{\theta \rho^{2}}=0 .
$$

Therefore, for $\theta>1$, when income distribution for the economy is more equal (i.e., when $\sigma_{m}$ is higher) the income tax rate is higher, and the growth rate $\gamma$ as in (6) is lower.

This result is intuitive. Because government spending is all for consumption, individuals in a democracy will try to allocate resources between public consumption and private consumption by comparing their marginal utility. Since individuals cannot provide public consumption services directly, government taxation and public provision come into play. With more income available to the median voter as a result of more equal distribution of income, people will vote for a higher income tax in order to allocate more resources to public consumption in their effort to equalize the marginal utility between private and public consumption.

Obviously enough, if all government spending is used for production, then government spending does not appear in the utility function, and the Barro-type production function will deliver a negative impact of income inequality on economic growth, the result given in Alesina and Rodrik (1994). The more realistic case is where government spending is partly for public consumption and partly for production, so the impact of income inequality on economic growth is ambiguous. Thus an effective empirical test of this more general theoretical result is an insignificant regression coefficient of income inequality on growth. We turn to this task in the next section.

\section{Emplrical Analysis}

This section provides an extensive analysis of the relationship between growth and income inequality. As the baseline regression, we reexamine the regression analysis in Alesina and Rodrik (1994) using a much expanded dataset by Deininger and Squire (1996); then, we extend the Alesina-Rodrik regressions to include more variables in recent growth empirics (see Levine and Renelt, 1992) and conduct the sensitivity analysis. 


\section{Data and Methodology}

Empirical studies in income distribution are often limited by the available data. In the case of Gini coefficients, the quality of the available data has been poor. The income inequality data we use here are based on a newly developed high-quality dataset of Gini coefficients by Deininger and Squire (1996). Starting with a total of 2,480 observations on Gini coefficients covering 112 developed and developing countries for the years 1947-94, several criteria were used to "cleanse" the data. First, all observations had to come from national household surveys for expenditure or income; second, the coverage had to be representative of the national population; and third, all sources of income and uses of expenditure had to be accounted for, including own-consumption. In addition, all observations had to be from countries with observations covering a reasonable time span in order to construct a panel dataset. Nevertheless, this panel data is highly unbalanced.

Note two points. First, the definition of what is being measured by the Gini coefficient in our sample varies across countries. Inequality can be measured by gross income, net income, or expenditure and it can be per capita or per household. Because variation in definition can undermine the international and intertemporal comparability of the data, proper adjustment is necessary. Therefore, we have adjusted the data following the procedure recommended by Deininger and Squire (1996). Specifically, we adjust for differences between income-based and expenditure-based coetficients by systematically increasing the latter by 6.6 points (on a 100-point scale), this being the average difference observed by Deininger and Squire (1996).

The data are averaged over five-year period as in $\mathrm{Li}$ et al. (1998). For most variables yearly observations are available, but the data on Gini coefficients are more limitedmany countries have fewer than ten observations, whiie only a few countries have more than 20 observations. Therefore, the five-year averages provide a more balanced panel dataset. For other variables the five-year averages reduce the short-run fluctuations and allow us to focus on the structural relationships we are most interested in.

These procedures, together with the data availability of other variables, resulted in a sample of 217 observations covering 46 countries. ${ }^{2}$ With this panel dataset, various pariei-data approaches can be applied. This makes our empirical analysis quite different from other recent studies, which are mostly based on cross-section regressions without paying much attention to the quality of the Gini data (see Benabou, 1996, for an exception) and with fewer observations.

Following recent empirics on economic growth, we also consider many other control variables in our regression analysis; e.g. the initial or lagged GDP level, the urbanization ratio, the population growth rate, financial development (defined as M2/GDP), openness (defined as export over GDP), domestic investment shares of GDP, black market premium and primary school enrollment ratio. These data are mostly obtained through the World Bank national accounts and Summers and Heston (1995). The black market premium and primary school enrollment ratio data are from Barro and Lee (1994). The primary years of schooling data are from Nehru et al. (1995).

As in Alesina and Rodrik (1994), the democracy dummy variable is used to control for the difference between democratic and nondemocratic countries. A country is classified as democratic if its civil liberty index is less or equal to two. ${ }^{3}$

\section{Baseline Regression Results}

Following Alesina and Rodrik, we examine the following base regression in its linear form. 


$$
G_{i t}=f\left(G I N I_{i t-l}, G D P_{i s-1,}, M Y P R_{i s-1}\right)+u_{n v}
$$

where $i=1,2, \ldots, N$ (number of countries) and $t=1,2, \ldots, T$ (five-year time period). $G_{i t}$ is the real GDP growth rate; $\mathrm{GINI}_{i t-1}$ is the lagged (for a five-year period) Gini coefficient; $\mathrm{GDP}_{i, r-1}$ is the lagged per capita real GDP level; and $\mathrm{MYPR}_{i,-1}$ is the lagged primary school enrollment ratio. The baseline regression in Alesina and Rodrik is a cross-sectional regression. The right-hand side variables are all initial values in the 1960 s. With panel data we use the lagged values in (16) instead.

Our focus is to investigate the relationship between growth and income inequality, while controlling the effects of GDP and education level as emphasized in many recent growth literature. The (lagged) GDP level will account for the issues related to convergence; and the (lagged) education level is a proxy for the initial level of human capital. The problem of endogeneity can usually be corrected using the instrumental variables method. However, since all the right-hand side variables in our baseline regression are lagged for a five-year period, this does not seem to cause serious estimation problems ${ }^{4}$

This dataset allows us to consider various specifications for panel data models. We have estimated the base regression using both the fixed-effects and the randomeffects models. Time-specific effects are also considered, as well as time-period dummy variables. By construction there are a total of nine five-year periods denoted as YDMI to YDM9. Because the first four have only a few observations together, the timespecific effects for these time periods are not evaluated. Note that in the randomeffects model the time-specific dummy variables are the same as in the fixed-effects model.

Now we turn to the discussion of the baseline estimation. We have considered four variations: (1) the base regression, (2) the base regression with time-specific dummy variables, (3) the base regression with democratic dummy variables, and (4) the base regression with democratic dummy and tinte-specific dummy variables. As Table 1 shows, the regression coefficients of the Gini ccefficient for both models are positive in all the four cases. In all cases the fixed-effects model yields significant estimates, whereas in two cases the random-effects model also yields significant estimates. This is very distinct from the findings in earlier studies by Alesina and Rodrik (1994) and Persson and Tabellini (1994), who find a significant and negative relationship between growth and income inequality. Our finding is consistent with the general theoretical prediction that income inequality and economics growth relates to each other ambiguously, in general, and positively, sometimes. As stated in the theoretical section, when government revenues collected through income taxation are used to finance public consumption instead of production, a more equal income distribution (measured by a lower Gini coefficient) may lead to a higher income tax rate and accordingly lower economic growth. Other theoretical studies have also pointed out possible positive associations between inequality and growth through different channels. For example, in a nonoverlapping generations model with voting, Perroti (1993) finds that a very egalitarian but poor economy will not be able to start the growth process. By contrast, an economy with a very unequal income distribution is in the best position to achieve a high initial rate of growth. Much earlier theoretical studies by Lewis (1954), Kaldor (1957), and Pasinetti (1962) have also predicted this positive association. According to Lewis, entrepreneurs save a larger fraction of their profit income than the other groups in the economy, and income inequality can lead to more savings for the rich and faster growth for the economy. Of course, Kaldor takes the saving rate of the working class to be zero. Thus income inequality can generate high savings rates and growth rates if 


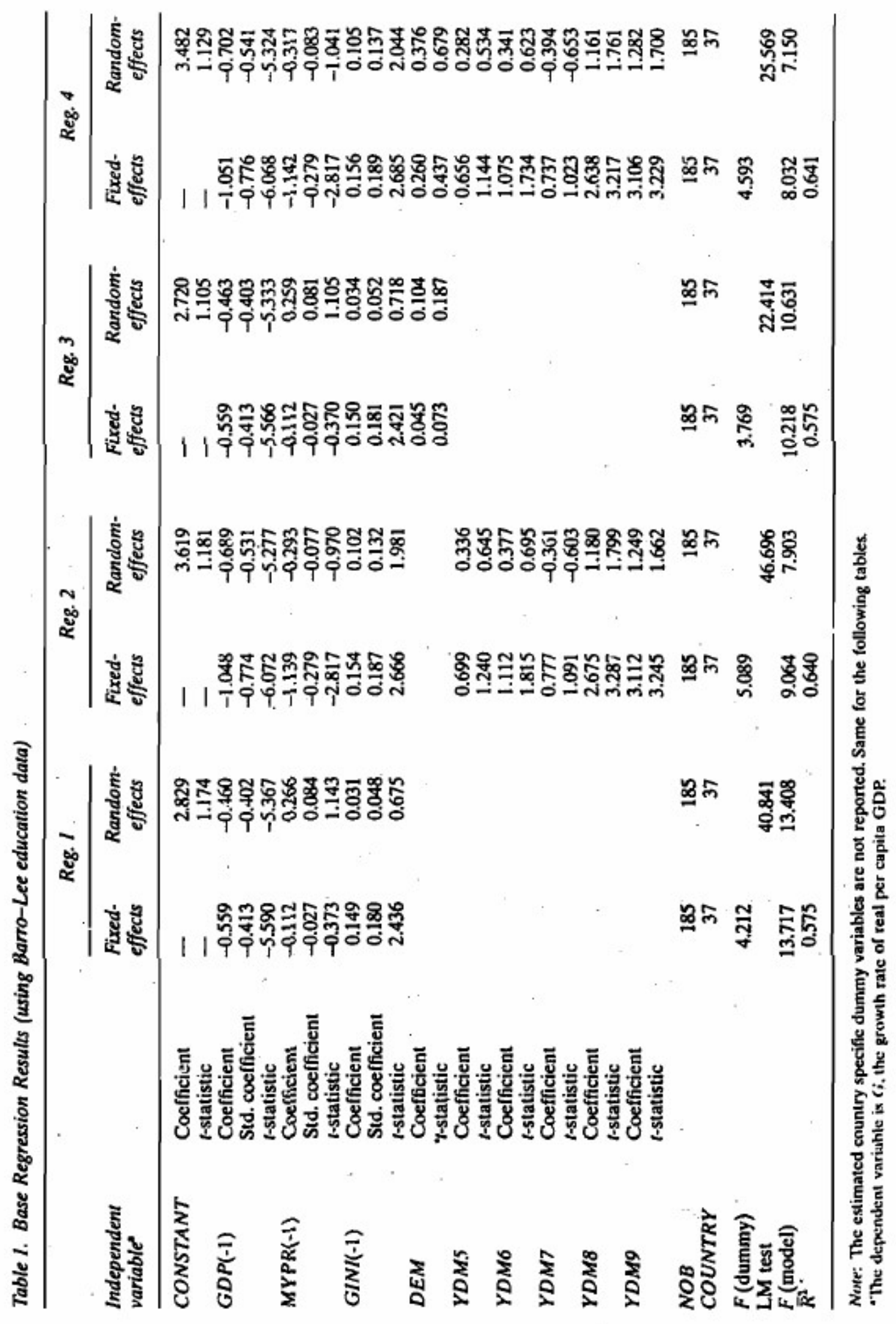


the rich have a larger share of income, or if income is more unequally distributed in the economy.

We can also notice some simple empirical facts. In our sample, the developed countries have a more equal income distribution than the developing ones (with the mean values of the Gini coefficients for the two groups being 33.51 and 40.65 , respectively), but developed countries have much higher income tax rates and not very high income growth rates (with the mean value $2.25 \%$ ) compared with developing countries in our sample. The difference in growth rates between the developed countries and many East Asian developing countries is even larger in recent years. The experience in developed countries seems to suggest that more equal income distribution leads to higher income taxation and perhaps relatively lower economic growth.

In Table 1, standardized regression coefficients are abbreviated as "Std. coefficients." For the fixed-effects model, the standardized regression coefficients for the Gini coefficient range from 0.18 to 0.19 . This means that, for one-standard-deviation increase in the Gini coefficient, there will be an increase of $0.45-0.48 \%$ in the rate of economic growth. For the random-effects model (two significant cases) the standardized regression coefficients range from 0.13 to 0.14 . Correspondingly, for one-standarddeviation increase in the Gini coefficient, there will be an increase of $0.33-0.35 \%$ in the rate of economic growth.

For the other explanatory variables, the regression coefficients of initial or lagged GDP are negative and highly significant in all cases, which is consistent with the results of Alesina and Rodrik (1994). In particular, the mean standardized coefficients of the lagged GDP are -0.60 for the fixed-effects model and -0.47 for the random-effects model. Thus for one-standard-deviation increase in the real GDP level, the decrease in the rate of economic growth will be $1.5 \%$ for the fixed-effects model and $1.2 \%$ for the random-effects model. Thus the lagged real GDP level has a much stronger standardized effect (more than three times) than that of the GINI coefficients. As in Alesina and Rodrik, the democratic dummy variable does not have a significant coefficient.

For the primary school enrollment ratio, the regression coefficients are negative and significant in two cases (both in the fixed-effects model). In other cases, they are mostly negative and insignificant. This finding is different from Alesina and Rodrik, which shows positive and significant coefficients for this variable. Other studies also report a negative association between education and economic growth. For example, Pritchett (1996) finds that the estimated impact of growth of human capital on economic growth is large, strongly significant and negative. Furthermore. period 8 (1985-89) and period $9(1990-94)$ time-specific dummy variables are significant in two cases. For other time periods they are not significant. It is interesting to find that the magnitude of the regression coefficients of the time-specific dummy variables increases over time. This result seems to suggest that economic growth has been relatively faster in recent years.

The above baseline regressions use the Barro-Lee primary school enrollment ratio data, the same variable used in Alesina and Rodrik (1994), which makes our results comparable. Note that only 37 of the 46 countries have data on this variable, and nine countries are excluded from the sample. Nehru et al. (1995) have constructed a dataset on human capital stock in developing and industrial countries. Using the primary years of schooling variable in Nehru et al. (1995), we are able to estimate the full sample baseline regression. The consequent results are summarized in Table $2{ }^{5}$ The results are similar to those discussed in Table 1. In particular, lagged real GDP has negative and significant regression coefficients whereas GINI positive and significant regression coefficients. The standardized coefficients of the two variables are similar in magnitude 
Table 2. Base Regression Results (using Nehru education data)

\begin{tabular}{|c|c|c|c|c|c|}
\hline $\begin{array}{l}\text { Independent } \\
\text { variable }\end{array}$ & & (1) & (2) & (3) & (4) \\
\hline \multirow[t]{3}{*}{$G D P(-1)$} & Coefficient & -0.640 & -0.834 & -0.642 & -0.836 \\
\hline & Std. coefficient & -0.428 & -0.558 & -0.429 & -0.559 \\
\hline & $t$-statistic & -6.091 & -5.554 & -6.079 & -5.541 \\
\hline \multirow[t]{3}{*}{ PYR(-1) } & Coefficient & -0.153 & -0.420 & -0.155 & -0.421 \\
\hline & Std. coefficient & -0.038 & -0.105 & -0.039 & -0.105 \\
\hline & $t$-statistic & -0.546 & -1.378 & -0.548 & -1.378 \\
\hline \multirow[t]{3}{*}{$G I N I(-1)$} & Coefficient & 0.165 & 0.182 & 0.167 & 0.183 \\
\hline & Std. coefficient & 0.177 & 0.195 & 0.179 & 0.196 \\
\hline & t-statistic & 2.588 & 2.897 & 2.595 & 2.897 \\
\hline \multirow[t]{2}{*}{$D E M$} & Coefficient & & & 0.179 & 0.140 \\
\hline & t-statistic & & & 0.276 & 0.213 \\
\hline \multirow[t]{2}{*}{ YDMS } & Coefficient & & 0.591 & & 0.563 \\
\hline & $t$-statistic & & 0.978 & & 0.908 \\
\hline \multirow[t]{2}{*}{ YDM6 } & Coefficient & & 0.849 & & 0.825 \\
\hline & t-statistic & & 1.360 & & 1.295 \\
\hline \multirow[t]{2}{*}{$Y D M 7$} & Coefficient & & 0.197 & & 0.171 \\
\hline & t-statistic & & 0.285 & & 0.243 \\
\hline \multirow[t]{2}{*}{ YDM8 } & Coefficient & & 1.888 & & 1.864 \\
\hline & $t$-statistic & & 2.506 & & 2.440 \\
\hline \multirow[t]{2}{*}{$Y D M 9$} & Coefficient & & 1.376 & & 1.366 \\
\hline & t-statistic & & 1.618 & & 1.599 \\
\hline$N O B$ & & 217 & 217. & 217 & $21 \bar{T}$ \\
\hline COUNTRY & & 46 & 46 & 46 & 46 \\
\hline$F$ (dummy) & & 4.755 & 4.859 & 4.669 & 4.692 \\
\hline$F$ (model) & & 17.736 & 9.091 & 13.248 & 8.039 \\
\hline $\bar{R}^{2}$ & & 0.582 & 0.620 & 0.583 & 0.620 \\
\hline
\end{tabular}

Note: See Table 1 note.

to those of the regressions reported in Table 1. For example, the average standardized coefficient for lagged real $G D P$ is 0.49 , whereas for $G I N I$ it is 0.19 . The primary years of schooling do not seem to significantly affect growth, however, the regression coefficients are all negative. Other dummy variables are insignificant most of the time. Thus the base regression results are fairly consistent for both the subsample and the full sample estimation results.

It is important to point out that we use panel data models, whereas Alesina and Rodrik used a cross-sectional dataset to discuss the relationship between growth and income distribution. They found that income inequality had a significant negative effect on growth. The basic implication of their model is that the more unequal the initial income distribution, the lower the rate of subsequent economic growth. The theoretical link between income inequality and growth emerges from redistributive policies. In their model the distribution of income is predetermined and remains constant over time. However, a more realistic assumption is that both growth and distribution change over time. For example, as emphasized by Atkinson (1997), in the United States, the Gini coefficient of inequality for household income sometimes increased and some- 
times decreased by three and one haif percentage points from 1950 to 1992 . According to the estimates by Goodman and Webb (1994), between 1977 and 1991, the UK Gini coefficients rose by 10 percentage points. These large changes in income distribution and their impact on economic growth will not be fully recovered if we take a 30 year average value. Using a panel data model with a five-year lag in income inequality has the advantage of revealing the dynamic interaction between distribution and growth. Given this consideration, it is not surprising to see that our empirical results have shown a positive, and often significant, relationship between growth and income inequality.

It will be important to examine whether we can duplicate the Alesina-Rodrik and Persson-Tabellini results if we estimate a similar cross-sectional regression on the basis of our new dataset. The cross-sectional regression we consider is as follows:

$$
G(60-90)_{i}=f\left(G I N I 60_{i}, G D P 60_{i}, M Y P R 60_{i}, L D G I N 160_{i}\right)+u_{i},
$$

where $i(i=1,2, \ldots, N)$ is the country index; $G(60-90)$ is the average growth rate between 1960 and 1990; and GINI60, GDP60, MYPRó and LDGINI60 (GINI coefficient on land distribution) are initial values over five years between 1960 and 1964. Note that for some of the initial $G I N I$, we use the five-year average between 1935 and 1969 or between 1970 and 1964 if there are no data for the period 1960-64. The time span is long enough for the growth rate, so the endogeneity problem of initial GINI seems to be a minor issue and the application of 2SLS or instrumental variables estimation suggested by Alesina and Rodrik (1994) is not considered here. We summarize the OLS results for the baseline regression using the cross-sectional data in Table 3. The first set of regressions ( 1 to 4 ) are hased on the Barro-Lee primary school enrollment ratio, whereas the second set (5 to 8) are based on Nehru et al. (1995) primary schooling years, to allow for a larger sample. The results are similar to those discussed by Alesina and Rodrik (1994). In particular, both the income distribution GINI and the land distribution $G I N I$ have negative and significant coefficients with their standardized coefficients approximately of the same magnitude. Note that, while all other variables remain to have the same signs in both the panel data models and the cross-sectional data regressions, the GINI has completely different signs. Thus by allowing the dynamic interaction between distribution and growth and also the difference between individual countries, we are abie to extend the resuits in Alesina and Rodrik (1994), and Persson and Tabellini (1994), and present some supporting evidence for an ambiguous or even a positive relationship between income distribution and growth. In passing, we also note that in a cross-section study, Deininger and Squire (1997) have produced a negative but insignificant relationship between income inequality and economic growth for $1960-92$ by including more explanatory variables in addition to the ones in the Alesina-Rodrik estimations. But our finding of a significant, positive association stands in sharp contrast to the findings of all the aforementioned empirical studies.

Overall, the relationship between income distribution and growth is a complicated theoretical and empirical issue. On a theoretical basis the relationship can be of any sign. On an empirical basis the relationship can be both positive and negative, depending on whether we allow enough variations in income inequality over time. When we extend the discussion in Alesina and Rodrik (1994) by considering the dynamic relationship between growth and income distribution, we can even find a very strong positive relationship between the two. 
Table 3. Base Regression Results: Cross-Sectional Data

\begin{tabular}{|c|c|c|c|c|c|c|c|c|c|}
\hline $\begin{array}{l}\text { Independent } \\
\text { variable* }\end{array}$ & & (I) & (2) & (3) & (4) & (5) & (6) & (7) & (8) \\
\hline \multirow[t]{2}{*}{ CONSTANT } & Coefficient & 7.280 & 8.479 & 7.240 & 8.582 & 5.785 & 7.150 & 6.525 & 7.886 \\
\hline & t-statistic & 5.409 & 6.790 & 5.597 & 7.479 & 4.077 & 6.360 & 5.225 & 8.005 \\
\hline \multirow[t]{3}{*}{ GDP64 } & Coefficient & -0.367 & -0.276 & -0.254 & -0.167 & -0.286 & -0.227 & -0.246 & -0.168 \\
\hline & Std. coefficient & -0.693 & -0.578 & -0.479 & -0.348 & -0.524 & -0.491 & -0.483 & -0.362 \\
\hline & t-statistic & -2.449 & -2.186 & -1.634 & -1.344 & -2.874 & -3.112 & -1.993 & -1.808 \\
\hline \multirow[t]{3}{*}{ MYPR64 } & Coefficient & 0.160 & 0.033 & 0.249 & 0.110 & & & & \\
\hline & Std. coefficient & 0.249 & 0.056 & 0.389 & 0.187 & & & & \\
\hline & t-statistic & 0.933 & 0.227 & 1.459 & 0.809 & & & & \\
\hline \multirow[t]{3}{*}{ PYR64 } & Coefficient & & & & & 0.192 & 0.091 & 0.299 & 0.173 \\
\hline & Std. coefficient & & & & & 0.245 & 0.135 & 0.401 & 0.250 \\
\hline & l-siatistic & & & & & 1.421 & 0.903 & 2.488 & 1.887 \\
\hline \multirow[t]{3}{*}{ GINI64 } & Coefficient & -0.089 & -0.066 & -0.092 & -0.071 & -0.060 & -0.038 & -0.081 & -0.059 \\
\hline & Std. Coefficient & -0.568 & -0.473 & -0.590 & -0.506 & -0.375 & -0.282 & -0.525 & -0.425 \\
\hline & r-statistic & -3.318 & -2.590 & -3.577 & -3.007 & -2.216 & -1.774 & -3.324 & -2.967 \\
\hline \multirow[t]{3}{*}{ LDGINI64 } & Coefficient & & -0.030 & & -0.030 & & -0.034 & & -0.031 \\
\hline & Std. coefficient & & -0.432 & & -0.439 & & -0.489 & & -0.452 \\
\hline & I-statistic & & $-2,769$ & & -3.059 & & -3.593 & & -3.718 \\
\hline$D E M$ & Coefficient & & & -1.321 & -1.287 & & & -0.919 & -1.061 \\
\hline & t-statistic & & & -1.933 & -2.527 & & & -1.536 & -2.391 \\
\hline$N O B$ & . & 37 & 34 & 37 & 34 & 42 & 39 & 40 & 38 \\
\hline$F$ (model) & & 4.485 & 7.351 & 4.577 & 8.250 & 3.490 & 7.707 & 5.798 & 11.099 \\
\hline$R^{2}$ & & 0.225 & 0.435 & 0.284 & 0.523 & 0.154 & 0.414 & 0.330 & 0.577 \\
\hline
\end{tabular}

-The dependent variable is $G$. the average growth rate of real per capita GDP between 1960 and 1990 .

\section{Sensitivity Analysis}

To examine the robustness of our baseline regression results, we extend the base regression by adding more variables commonly used in growth empirics; see Levine and Renelt (1992), among many others. These variables, which we call sensitivity variables, include the population growth iate $(P G R W)$, urbanization ratio $(U R B)$, openness $(X G D P)$, investment share $(I N V S H R)$, black market premium $(B M P)$, and financial development $(F N D P)$. Obviously enough, some of these variables such as investment share and openness ate endogenous. However, even using lagged values of these variables as instruments does not change the results significantly. Four groups of regressions were estimated based on the fixed-effects model. Since the baseline regression results suggest that adding democratic and time-specific dumıny variables does not seem to change the results significantly, these dummy variables are not considered here. The regressions in the first two sets are backward stepwise regressions. The sensitivity variables are first all added and then the least insignificant one is deleted in a backward way. See the results in Table 4 where regressions 1 to 4 are based on the Barro-Lee education data (the subsample) and regressions 5 to 8 are based on the education data (the full sample) from Nehru et al. (1995). In the third group of sensitivity regressions each regression is obtained by adding only one sensitivity variable to the base regression each time. The results are reported in Table 5 (based on the Barro-Lee education data). Then we use the Nehru et al. (1995) education data to check the sensitivity of regression results for the full sample. The sensitivity analysis results for the last group are reported in Table 6. 
Table 4. Sensitivity Analysis I: Stepwise Regressions

\begin{tabular}{|c|c|c|c|c|c|c|c|c|c|}
\hline $\begin{array}{l}\text { Independent } \\
\text { variable }\end{array}$ & & $(I)$ & (2) & (3) & (4) & (5) & (6) & (7) & (8) \\
\hline \multirow[t]{3}{*}{$G D P(-1)$} & Coefificient & -0.690 & -0.655 & -0.626 & -0.730 & -0.573 & -0.587 & -0.570 & -0.600 \\
\hline & Std. coefficient & -0.546 & -0.519 & -0.463 & -0.539 & -0.428 & -0.455 & -0.441 & -0.401 \\
\hline & t-statistic & -4.872 & -5.173 & -5.176 & -6.638 & $-4,821$ & -5.542 & -5.420 & -5.217 \\
\hline \multirow[t]{3}{*}{$M Y P R(-1)$} & Coefficient & -1.128 & -1.073 & -0.586 & -1.103 & & & & \\
\hline & Std. coefficient & -0.249 & -0.237 & -0.143 & -0.270 & & & & \\
\hline & I-statistic & -2.302 & -2.234 & -1.353 & -3.166 & & & & \\
\hline \multirow[t]{3}{*}{ PYR(-1) } & Coefficient & & & & & -0.326 & -0.316 & -0.314 & -0.095 \\
\hline & Std. coefficient & & & & & -0.091 & -0.088 & -0.088 & -0.024 \\
\hline & $t$-statistic & & & & & -1.268 & -1.232 & -1.222 & -0.325 \\
\hline \multirow[t]{3}{*}{$\operatorname{GINI(-1)}$} & Coefficient & 0.081 & 0.080 & 0.080 & 0.091 & 0.108 & 0.107 & 0.120 & 0.103 \\
\hline & Std coefficient & 0.101 & 0.099 & 0.097 & 0.110 & 0.127 & 0.126 & 0.142 & 0.110 \\
\hline & t-statistic & 1.347 & 1.320 & 1.374 & 1.543 & 1.771 & 1.766 & 2.006 & 1.635 \\
\hline \multirow[t]{3}{*}{ PGRW } & Coefficient & -1.811 & -1.837 & -1.623 & -1.268 & -0.188 & -0.145 & -0.136 & -0.118 \\
\hline & Std. coefficient & -0.268 & -0.273 & -0.239 & -0.186 & -0.343 & -0.266 & -0.249 & -0.222 \\
\hline & I-statistic & -2.831 & -2.872 & -2.586 & -2.088 & -3.519 & -3.027 & -2.869 & -2.488 \\
\hline \multirow[t]{3}{*}{$X G D P$} & Coefficient & 0.063 & 0.058 & 0.111 & 0.097 & -1.741 & -1.589 & -1.858 & -1.646 \\
\hline & Std. coefficient & 0.146 & 0.136 & C.283. & 0.247 & -0.243 & -0.239 & -0.280 & -0.224 \\
\hline & t-statistic & 1.552 & 1.487 & 3.326 & 2.939 & -2.810 & -2.634 & -3.316 & -2.661 \\
\hline \multirow[t]{3}{*}{ INVSHR } & Coefficient & 0.137 & 0.137 & 0.137 & 0.135 & 0.109 & 0.115 & 0.117 & 0.174 \\
\hline & std. coefficient & 0.236 & 0.237 & 0.235 & 0.232 & 0.172 & 0.183 & 0.187 & 0.258 \\
\hline & s-statistic & 3.000 & 3.014 & 3.246 & 3.113 & 2.356 & 2.539 & 2.585 & 3.803 \\
\hline \multirow[t]{3}{*}{ URB } & Coefficient & -0.086 & $-0.080^{\circ}$ & -0.114 & & -0.585 & -0.579 & -0.628 & \\
\hline & Std. coefficient & -0.166 & -0.154 & -0.249 & & -0.108 & -0.108 & -0.117 & \\
\hline & t-statistic & -1.264 & -1.192 & -1.972 & & -1.598 & -1.614 & -1.758 & \\
\hline \multirow[t]{3}{*}{$B M P$} & Coefficient & -0.479 & -0.460 & & & 0.075 & 0.035 & & \\
\hline & Std. coefficient & -0.086 & -0.083 & & & 0.166 & 0.100 & & \\
\hline & I-statistic & -1.177 & -1.129 & & & 1.923 & 1.189 & & \\
\hline \multirow[t]{3}{*}{ FNDP } & Coefficient & 1.246 & & & & 0.583 & & & \\
\hline & Std. coefficient & 0.062 & & & & 0.028 & & & \\
\hline & t-statistic & 0.730 & & & & 0.364 . & & & \\
\hline$N O B$ & . & 165 & 166 & 185 & 185 & 183 & 187 & 187 & 217 \\
\hline COUNTRY & & 37 & 37 & 37 & 37 & 43 & 43 & 43 & 46 \\
\hline$F$ (dummy) & & 3.059 & 3.029 & 2.916 & 2.757 & 3.363 & 3.526 & 3.630 & 4.028 \\
\hline$F$ (model) & & 9.578 & 10.483 & 11.751 & 12.802 & 11.204 & 12.358 & 13.879 & 13.47 \\
\hline$R^{2}$ & & 0.696 & 0.692 & 0.655 & 0.646 & 0.702 & 0.697 & 0.694 & 0.631 \\
\hline
\end{tabular}

-The dependent variable is $G$, the growth rate of real per capita GDP.

First we discuss the stepwise regressions in Table 4. For the base regression variables, the regression coefficients of $G D P$ are still negative and significant in all the four cases. Primary education enrollment ratio has negative coefficients, which are significant in three out of the four cases. The regression coefficients of the GINI coefficient are still positive but insignificant. Note that they are significant in the base regressions (the fixed-effects model). These insignificant, positive coefficients further support the ambiguity between growth and income inequality derived from our general theoretical model.

For the sensitivity variables, the estimates for the growth effects of financial development (with positive coefficients) and black market premium (with negative coefficients) have the same signs as in King and Levine (1993a,b), but they are not statistically significant. Therefore, they are deleted (see cases 1 and 2 ). The remaining 
Table 5. Sensitivity Analysis II: Based on the Barro-Lee Education Data

\begin{tabular}{|c|c|c|c|c|c|c|c|}
\hline $\begin{array}{l}\text { Independent } \\
\text { variable }\end{array}$ & & (l) & (2) & (3) & (4) & (5) & (6) \\
\hline \multirow[t]{3}{*}{$G D P(-1)$} & Coefficient & -0.699 & -0.690 & -0.512 & -0.547 & -0.588 & -0.628 \\
\hline & Std. coefficient & -0.516 & -0.510 & -0.378 & -0.404 & -0.466 & -0.480 \\
\hline & $t$-statistic & -6.252 & -6.697 & -5.249 & -4.327 & -6.107 & -5.561 \\
\hline \multirow[t]{3}{*}{$M Y P R(-1)$} & Coefficient & -0.568 & -0.681 & -0.317 & -0.056 & -0.580 & -0.105 \\
\hline & Std. coefficient & -0.139 & -0.167 & -0.077 & -0.014 & -0.128 & -0.026 \\
\hline & $t$-statistic & -1.656 & -2.059 & -1.069 & -0.120 & -1.681 & -0.340 \\
\hline \multirow[t]{3}{*}{ GINI $(-1)$} & Coefficient & 0.158 & 0.130 & 0.093 & 0.148 & 0.131 & 0.150 \\
\hline & Std. coefficient & 0.192 & 0.157 & 0.113 & 0.179 & 0.161 & 0.188 \\
\hline & -statistic & 2.636 & 2.192 & 1.522 & 2.407 & 2.104 & 2.545 \\
\hline \multirow[t]{3}{*}{ PGRW } & Coefficient & -1.656 & & & & & \\
\hline & Std. coefficient & -0.244 & & & & & \\
\hline & $t$-statistic & -2.607 & & & & & \\
\hline \multirow[t]{3}{*}{$X G D P$} & Coefficient & & 0.120 & & & & \\
\hline & Std, coefficient & & 0.305 & & & & \\
\hline & $t$-statistic & & 3.557 & & & & \\
\hline \multirow[t]{3}{*}{ INVSHR } & Coefficient & & & 0.151 & & & \\
\hline & Std. coefficient & & & 0.260 & & & \\
\hline & $t$-statistic & & & 3.423 & & & \\
\hline \multirow[t]{3}{*}{$U R B$} & Coefficient & & & & -0.009 & & \\
\hline & Std. coefficient & & & & -0.020 & & \\
\hline & $t$-statistic & & & & -0.159 & & \\
\hline \multirow[t]{3}{*}{$B M P$} & Coefficient & & & & & -0.791 & \\
\hline & Std. coefficient & & & & & -0.142 & \\
\hline & t-statistic & & & & & -1.873 & \\
\hline \multirow{3}{*}{ FNDP } & Coefficient & & & & & & 2.653 \\
\hline & Std. coefficient & & & & & & 0.134 \\
\hline & t-statistic & & & & & & 1.505 \\
\hline$N O B$ & & 185 & 185 & 185 & 185 & 166 & 183 \\
\hline COUNTRY & & 37 & 37 & 37 & 37 & 37 & 37 \\
\hline$F$ (dummy) & & 4.398 & 4.493 & 2.153 & 4.032 & 3.825 & 4.147 \\
\hline$F$ (model) & & 12.398 & 14.277 & 13.976 & 10.225 & 12.740 & 11.155 \\
\hline $\bar{R}^{2}$ & & 0.594 & 0.609 & 0.607 & 0.575 & 0.629 & 0.598 \\
\hline
\end{tabular}

-The dependent variable is $G$, the growth rate of real per capita GDP.

sensitivity variables in cases 3 and 4 are all significant. Population growth and urbanization have negative effects on growth, while openness and investment have positive effects. All of these follow the conventional wisdom.

Even though the positive association between inequality and growth has been produced in our two testing scenarios above, the change from significant coefficients for the Gini coefficients in our base regressions to nonsignificant ones in the sensitivity tests leads us to another step in our empirical examinations. One possible reason for this change is the correlation between the GINI coefficient and the sensitivity variables or the correlation between the sensitivity variables (the multicollinearity problem), or the correlation between growth and other sensitivity variables since pop- 
Table 6. Sensitivity Analysis III: Based on the Nehrt et al. (1995) Education Data

\begin{tabular}{|c|c|c|c|c|c|c|c|}
\hline $\begin{array}{l}\text { Independent } \\
\text { variablet }\end{array}$ & & (I) & (2) & (3) & (4) & (5) & (6) \\
\hline \multirow[t]{3}{*}{$G D P(-1)$} & Coefficient & -0.728 & -0.738 & -0.598 & -0.601 & -0.600 & -0.725 \\
\hline & Std. coefficient & -0.486 & -0.505 & -0.400 & -0.402 & -0.465 & -0.481 \\
\hline & t-statistic & -6.344 & -6.858 . & -5.830 & -5.192 & -6.474 & -5.906 \\
\hline \multirow[t]{3}{*}{$M Y P R(-1)$} & Coefficient & -0.312 & -0.298 & -0.170 & -0.057 & -0.357 & -0.158 \\
\hline & Std. coefficient & -0.078 & -0.076 & -0.042 & -0.014 & -0.100 & -0.040 \\
\hline & $t$-statistic & -1.067 & -1.086 & -0.624 & -0.186 & -1.385 & -0.569 \\
\hline \multirow[t]{2}{*}{ GINI(-1) } & Coefficient & 0.168 & 0.133 & 0.108 & 0.164 & 0.156 & 0.160 \\
\hline & Std. coefficient & 0.179 & 0.146 & 0.115 & 0.175 & 0.184 & 0.176 \\
\hline & t-statistic & 2.645 & 2.155 & 1.686 & 2.568 & 2.583 & 2.538 \\
\hline \multirow[t]{2}{*}{ PGRW } & Coefficient & -1.069 & & & & & \\
\hline & $\begin{array}{l}\text { Std. coefficient } \\
t \text {-statistic }\end{array}$ & $\begin{array}{l}-0.146 \\
-1.837\end{array}$ & & & & & \\
\hline \multirow[t]{3}{*}{$X G D P$} & Coefficient & & 0.071 & & & & \\
\hline & Std, coefficient & & 0.194 & & & & \\
\hline & t-statistic & & 2.628 & & & & \\
\hline \multirow[t]{2}{*}{ INVSHR } & Coefficient & & & 0.159 & & & \\
\hline & Std. coefficient & & & $\begin{array}{l}0.236 \\
3.453\end{array}$ & & & \\
\hline \multirow[t]{3}{*}{ URB } & Coefficient & & & & -0.036 & & \\
\hline & Std, coefficient & & & & -0.067 & & \\
\hline & t-statistic & & & & -0.802 & & \\
\hline \multirow[t]{3}{*}{$B M P$} & Coefficient & & & & & -0.792 & \\
\hline & Std. coefficient & & & & & -0.147 & \\
\hline & $t$-statistic & & & & & -2.109 & \\
\hline \multirow[t]{3}{*}{ FNDP } & Coefficient & & & & & & 2.581 \\
\hline & Std. coefficient & & & & & & 0.115 \\
\hline & t-statistic . & . & & & & & 1.443 \\
\hline$N O B$ & & 217 & 216 & 217 & 217 & 187 & 212 \\
\hline COUNTRY & & 46 & 46 & 46 & 46 & 43 & 46 \\
\hline$F$ (dummy) & & 4.871 & 5.067 & 3.693 & 4.712 & 4.151 & 4.093 \\
\hline$F($ model $)$ & & 14.334 & 15.888 & 17.148 & 13.434 & 16.799 & 13.568 \\
\hline & .. & 0.591 & 0.62 & 0.610 & 0.584 & 0.647 & 0.601 \\
\hline
\end{tabular}

-The dependent variable is $G$, the growth rate of real per capila GDP.

ulation growth, openness and the investment share can explain growth very well. For this reason, we have further estimated another two sets of sensitivity regressions by adding only one sensitivity variable into the base regression each time. See the results in Table 5 and Table 6 . The lagged GDP has a strong negative effect on growth in the presence of other sensitivity variables. Education has a negative but insignificant effect. Except for one regression (regression (3) in bóth Table 5 and Table 6 ) when the investment share is added, the regression coefficients of the GINI coefficient are all positive and significant: These two sets of estimations seem to confirm that the positive, significant association between inequality and growth in our baseline regression is robust. 


\section{Concluding Remarks}

In this paper, we have shown theoretically that income inequality may lead to higher economic growth if public consumption enters the utility function. Empirically, our baseline estimations and the sensitivity analysis have shown that income inequality is positively, and very often even significantly, associated with economic growth. These findings stand in sharp contrast to the significant negative association between inequality and growth found by Alesina and Rodrik (1994) and by Persson and Tabellini (1994).

In light of both theoretical models and empirical findings, we shall admit that the association between income inequality and economic growth is a very complicated matter (see much more on this point in Benabou (1996) and Perotti (1996a, b)). The positive effects of inequality on savings and growth in Lewis (1954) and Kaldor (1957) are intuitively appealing. The negative effects of inequality on growth in the Alesina-Rodrik and Persson-Tabellini models are also plausible. On the basis of simple empirical observations, neither positive nor negative association between inequality and growth shall be interpreted as causality from inequality to growth. To illustrate this point, we have a significant rising trend in the Gini coefficients for China in our dataset. In 1984, China had a relatively low Gini coefficient of household income at 25.7 on a scale of 100 . By 1992, China reached a relatively high Gini coefficient of income at 37.8. This rapid increase in income inequality (12-point rise in 8 years) is assuciated with the spectacular growth performance of $9.8 \%$ average growth in real GDP. But for the UK, the 10-point rise in the Gini coefficient of income inequality was associated with moderate (2-3\%) or even negative episodes of economic growth from 1977 to 1991 (Goodman and Webb, 1994). It would be of great interest to explore the dynamic interaction between inequality and growth for those countries with significant time trends in their income distribution. ${ }^{6}$

\section{References}

Alesina, A. and D. Rodrik, "Distributive Politics and Economic Growth," Quarterly Journal of Economics 109 (1994):465-90.

Arrow. K. and M. Kurz, Public Investment, the Rate of Return and Optimal Fiscal Policy, Baltimore, MD: Johns Hopkins University, 1970.

Atkinson, T., "Bring Income Distribution in from the Cold," Economic Journal 107 (1997): 297-321.

Banerjee, A. and A. Newman, "Occupational Choice and the Process of Development," Joumal of Political Economy 101 (1993):274-98.

Barro. R. "Government Spending in a Simple Model of Endogenous Growth," Joumal of Political Economy 98 (1990):S103-25.

Barro, R. and J. Lee, Data Set for a Panel of 138 Countries, 1994.

Benabou, R., "Inequality and Growth," in NBER Macroeconomics Annual, Cambridge, MA: MIT Press, 1096.

Deininger, K. and L. Squire, "Measuring Income Inequality: A New Data Base," World Bank Economic Review 10 (1996):565-91.

Deininger, K. and L. Squire, "Economic Growth and Income Inequality: Reexamining the Links," Finance and Development 34 (1997):38-41.

Galor, O. and I. Zeira, "Income Distribution and Macroeconomics," Review of Economic Studies 60 (1993):35-52.

Gastil, R: Freedom in the World, Westport, Greenwood, various issues.

Goodman, A. and S. Webb, "For Richer, For Poorer," Institute for Fiscal Studies Commentary No. 42, London, 1994. 
Greenwood, J. and B. Jovanovic. "Financial Development, Growth, and the Distribution of Income." Journal of Political Economy 98 (1990):1076-107.

Hall, R., "Intertemporal Substitution in Consumption," Journal of Political Economy 96 (1988): 339-57.

Kaldor, N., "A Model of Economic Growth." Economic Joumal 57 (1957):591-624.

King, R. and R. Levine, "Finance and Growth: Schumpeter Might Be Right," Quarterly Journal of Economics 108 (1993a):717-38.

King, R. and R. Levine, "Finance, Entrepreneurship, and Growth: Theory and Evidence," Journal of Monetary Economics 32 (1993b):513-42.

King, R. and S. Rebelo, "Public Policy, and Economic Growth: Developing Neoclassical Implications," Joumal of Political Economy 98 (1990):S126-50.

Levine, R. and D. Renelt, "A Sensitivity Analysis of Cross-Country Growth Regressions." American Economic Review 82 (1992):942-63.

Lewis, W. A., "Economic Development with Unlimited Supplies of Labor," The Manchester School 22 (1954):139-91.

Li, H., L. Squire and H. Zou, "Explaining International and Intertemporal Variations in Income Inequality." Economic Journal 108 (1998):26-43.

Nehru. V., E. Swanson, and A. Debey, "A New Database on Human Capital Stock in Developing and Industrial Countries: Sources, Methodology, and Results," Journal of Development Economics 46 (1995):379-401.

Pasinetti, L." "Rate of Profit and Income Distribution in Relation to the Rate of Economic Growth," Review of Economic Studies 29 (1962):267-79.

Perotti, R., "Political Equilibrium. Income Distrihutiun, and Growth," Review of Economic Studies 60 (1993):755-76.

Perotti, R.,"Growth, Income Distribution, and Democracy: What the Data Say," Journal of Economic Growth 1 (1996a):149-87.

Perotti, R., "Comment on Inequality and Growth." in NBER Macroeconomics Anmual, Cambridge, MA: MIT Press, $1996 \mathrm{~b}$.

Persson, T. and G. Tabellini, "Is Inequality Harmful for Growth? Theory and Evidence," American Economic Review 84 (1994):600-21.

Pritchett, L., "Where Has all the Education Gone?" Policy Research Working Paper No. 1581, World Bank, 1996.

Summers, R. and A. Heston. "Penn World Table (Mark 5.6)," 1995.

$\mathrm{Xu}, \mathrm{L}$. C. and H. Zou, "The Changes of Income Inequality in China," Policy Research Department, World Bank, Washington, DC, 1997.

\section{Notes}

1. Persson and Tabellini (1994) have shown a similar negative relationship between income inequality and economic growth in a two-period model. A variety of theoretical approaches can be found in Greenwood and Jovanovic (1990), Banerjee and Newman (1993), Galor and Zeira (1993), and Perroti (1993).

2. These countries are (by the World Bank and IMF three-letter country code): AUS, BEL. BGD, BGR, BRA, CAN, CHL, COL, CRI, CSK, DEU, DNK, DOM, ESP, FIN, FRA, GBR, HKG, HND, IUN, IDN, IND, IRN, ITA, JAM, JPN, KOR, LKA, MEX, MYS, NLD, NOR, NZL, PAK, PAN, PHL, POL, PRT, SGP, SWE, THA, TTO, TUN, USA, VEN, and YUG.

3. There are two indices in Gastil (various issues) measuring civil liberties and political rights, Since the two are highly correlated, we only use one of them-the civil liberty index-in our base regression but interpret it broadly to capture both civil liberties and political rights. We use the average index for the period 1972-89 as reported in Barro and Lee (1994). The index is defined from 1 to 7 , with 1 assigned to countries with the largest degree of civil liberties.

4. Since the growth rate is calculated based on the current and lagged period GDP and the lagged $G D P$ also appears on the right-hand side, we have reestimated regression (16) by replacing the lagged $G D P$ with $G D P$ lagged for two time periods (ten years). The estimation results 
did not seem to change. We have also estimated the baseline regression using the instrumental variables method, with the instrumental variables being the right-hand side variables lagged one additional time period. The change in the magnitudes and significance levels of the regression coefficients are small.

5. To conserve space, we report only the fixed-effects model results from now on. However, the random-effects model results are available from the authors.

6. Alesina and Rodrik (1994, p. 485) have also emphasized this point. See Atkinsos (1997), and $\mathrm{Xu}$ and Zou (1997) for explorations of the rising inequality in the UK and China, respectively. 